\title{
Ensino de Raciocínio Lógico e Computação para crianças: Experiências, Desafios e Possibilidades
}

\author{
Thâmillys Marques de Oliveira ${ }^{1}$, Willmara Marques Monteiro' ${ }^{1}$, Fábio Cristiano \\ Souza Oliveira ${ }^{1}$, Danielle Juliana Silva Martins ${ }^{1}$, Alessandra Luengo Latorre da \\ Silva ${ }^{1}$
}

\author{
${ }^{1}$ Instituto Federal de educacão, Ciência e Tecnologia do Sertão Pernambucano - \\ Campus Petrolina (IF SERTAO - PE). Departamento de Licenciatura em Computação. \\ Caixa Postal 15.064 - 91.501-970 - Petrolina - PE - Brazil
}

\section{\{thamillysmarques@gmail.com, willmaramarques@gmail.com, fabio.cristianodifsertao-pe.edu.br}

\begin{abstract}
This work reports an experience of teaching Logical Reasoning and Computational Thinking to students basic education from public schools of the state of Pernambuco using dynamics, gamification and robotics.
\end{abstract}

\begin{abstract}
Resumo. Este trabalho relata uma experiência de ensino de Raciocínio Lógico e Pensamento Computacional para alunos da educação básica da rede pública do estado de Pernambuco com o emprego de dinâmicas; gamificação e robótica educacional.
\end{abstract}

\section{Introdução}

No Brasil, atualmente, o estudo dos conceitos relativos a computação ou informática é reservado a pessoas que escolhem cursar graduação ou pós-graduação na área. Contudo, o ACM Model Curriculum for K-12 Computer Science (CSTA, 2011) diz que o ensino da computação deve se estender a todos os profissionais nas diversas áreas (saúde, engenharia, esportes, entretenimento, comunicação...). E vai além, defende que o ensino do pensamento computacional deve ser ofertado também na educação básica.

Segundo Paulo Blinkstein, o pensamento computacional é um processo de pensar envolvido na formulação de problemas e das suas soluções, tendo como base os fundamentos da Ciência da Computação (BLINKSTEIN, 2008). O autor enfatiza que o pensamento computacional faz parte de uma série de habilidades necessárias ao pleno exercício da cidadania neste século.

Nesse contexto o ensino da computação se difere do ensino da informática. Ensinar apenas aplicativos como processador de texto e planilha eletrônica seria como ensinar a usar calculadoras e não a calcular, no ensino da Matemática (NUNES, 2008). Ensinar conceitos básicos de computação é fundamental para desenvolver nas crianças criatividade, raciocínio lógico, dinamismo e pensamento algorítmico.

Tanto o pensamento computacional como o raciocínio lógico, promove uma maior capacidade de dedução e conclusão de problemas (SICA, 2011). Isto é altamente

*Ferramenta gratuita para criação de quiz online 
encorajado pela Sociedade Brasileira de Computação, que afirma que o ensino da computação deve ser implantado no Ensino Fundamental, assim como outras ciências.

Considerando a relevância do que foi exposto, este trabalho apresenta um relato de ensino de raciocínio lógico e computação para crianças, decorrentes de atividades desenvolvidas no Projeto Programadores do Futuro do Instituto Federal de Educação, Ciência e Tecnologia do Sertão Pernambucano, campus Petrolina, no ano de 2016. As metodologias, bem como os resultados obtidos, basearam-se na realização de atividades lúdicas, através de dinâmicas, de estratégias de gamificação e robótica educacional.

Este trabalho apresenta a seguinte estrutura: na seção 2 será apresentada uma breve descrição do projeto; na seção 3 serão apresentados conceitos de gamificação e gamificação na educação; na seção 4 será apresentado o conceito de robótica educacional; na seção 5 estão descritos os passos das metodologias utilizadas e na seção 6 os resultados obtidos.

\section{Programadores do Futuro}

O Projeto "Programadores do Futuro" surgiu inicialmente com a proposta de preparar crianças e jovens para a Olimpíada Brasileira de Informática (OBI), visando desenvolver habilidades necessárias ao século XXI, como a concentração, o raciocínio lógico e matemático, sistematização do pensamento, entre outros. No primeiro ano obteve-se a participação de 125 crianças da comunidade local.

Os resultados obtidos no ano de 2015 demonstraram que o Projeto logrou êxito. Assim, para 2016 foram feitos aperfeiçoamentos, que incluíam além do treinamento para a OBI, uma inserção de conteúdos relacionados ao pensamento computacional e robótica educativa com a estratégia de gamificação. Todas as aulas eram ministradas por alunos da instituição; licenciandos em computação e alunos do ensino médio integrado ao técnico em informática.

Neste artigo será relatada a experiência vivenciada por uma aluna do curso Licenciatura em Computação do IF Sertão PE, em aulas ministradas no Projeto "Programadores do Futuro" em uma turma de 15 alunos, no período de Janeiro à Novembro de 2016.

\section{O que é a gamificação?}

A gamificação (do inglês "gamification") tem sido abordada por muitos estudiosos, pesquisadores e curiosos nos últimos anos. Alguns a chamam de fenômeno (FARDO, 2013); técnica (BORGES et al. 2013); metodologia (ROCHA, 2014); entre outros. O termo começou a ser utilizado em 2010 e se originou como metodologia aplicada a marketing e aplicações para a web com a finalidade de engajar e fidelizar clientes (ZICHERMANN e CUNNINGHAM, 2012).

A gamificação tem como base o pensar como se de fato estivesse em um jogo, utilizando sistemáticas, regras e mecânicas do 'jogar' em um contexto de não jogo (JUCÁ e ROLIM, 2013). Ela serve como possibilidade de resolução de problemas e engajamento de um determinado público. Contudo, segundo Vianna et al. (2013), isso não significa necessariamente, a utilização de jogos ou até mesmo tecnologias computacionais e gráficas, mas à aplicação de elementos de jogos - dinâmicas,

*Ferramenta gratuita para criação de quiz online 
ludicidade, pontuação, regras, estética - para se alcançar os objetivos obtidos com o ato de jogar.

Zichermann e Cunningaham (2011) afirmam que a gamificação aprofunda os níveis de envolvimento do indivíduo para a resolução de problemas. Segundo os autores as pessoas são induzidas a jogar por quatro motivos específicos: para alívio do stress; obtenção de domínio sobre determinado conteúdo; como meio de socialização e entretenimento. Além disso, os autores abordam aspectos de diversão durante o ato de jogar: quando há uma competição e o jogador procura obter a vitória; quando há a imersão na exploração de um universo; quando há envolvimento entre os jogadores e quando o jogador tem sua emoção alterada pelo jogo.

Neste aspecto, pode-se utilizar gamificação em ambientes onde o público necessita de um estímulo (CAMPOS et al. 2015). Em se tratando de mecânicas de jogos, Vianna et al. (2013) salienta que motivação baseia-se em experiências vivenciadas por pessoas, buscando novas perspectivas. Permitindo um estímulo à criatividade, a autonomia de pensamento e proporcionando bem-estar ao jogador.

\subsection{A Gamificação na Educação}

Direta ou indiretamente o jogo sempre está presente no cotidiano das pessoas. Segundo Orrico (2012) no mundo existem 1,2 bilhões de jogadores, onde 700 milhões jogam online, correspondendo a 44\% da população online. Kapp et al. (2012) cita em seu livro "The gamification of learning and instruction" que o game possui aspectos bem distintos: regras, interatividade, feedback das ações do jogador... Gerando envolvimento emocional. Também potencializam a aprendizagem em diversas áreas (OLIVEIRA et al. 2016).

Um ponto imprescindível nos jogos é a liberdade de escolha, querer jogar depende exclusivamente do jogador (BITENCOURT, 2014). Remetendo ao ambiente educacional o jogo perde seu principal elemento, pois, comumente está inserido em processos de ensino aprendizagem (ALVES, 2014).

É sumamente importante evidenciar que a gamificação não propõe a criação de jogos para o ensino, mas, o uso de estratégias e do raciocínio presentes nos jogos, para resolução de problemas (OLIVEIRA et al. 2016).

No tocante a forma de inserção no ambiente educativo, varia de acordo com o público e objetivos a serem atingidos (LEADLEY, 2011). Pode-se inserir mecanismos de jogos - pontos, recompensas, tabelas de líderes - para envolver os indivíduos; ou buscar uma experiência mais exímia, trazendo os jogadores para o contexto em que estão trabalhando (ALVES, 2014).

Um exemplo de gamificação na educação amplamente difundido é o da Escola pública de Nova York Quest To Learn (Q2L), fundada em 2009. A Escola entrou para a história como a primeira a possuir o currículo baseado em jogos; e atende alunos do $6^{\circ}$ ano do ensino fundamental até o $3^{\circ}$ ano do ensino médio. Nela os alunos são instigados a participar ativamente dos processos de ensino-aprendizagem. Exatamente como objetiva a gamificação (WERBACH e HUNTER, 2012).

*Ferramenta gratuita para criação de quiz online 
Gamificar pode ser uma palavra prioritária na educação para construção de uma rede colaborativa e dinâmica onde docentes e discentes unem-se na empreitada de aprender de forma lúdica, sem preocupações com escalas de médias e desempenhos quantitativos (JOHNSON, 2011). Entretanto, é importante salientar que resgatar a alegria do aprender no ambiente escolar vai além dos elementos que compõem a gamificação (FARDO, 2013).

\section{Robótica Educacional}

Steffen (2009) define a robótica como uma área do conhecimento relativa ao controle e construção de robôs. Robô é uma derivação da palavra de origem tcheca robotinik que quer dizer "servo". Através do bioquímico Isaac Asimov popularizou-se o termo robô. O famoso cientista escreveu inúmeras publicações envolvendo a temática.

No meio educacional a robótica pode ser interpretada como o emprego da robótica industrial, isto é, inserção de conceitos básicos de inteligência artificial, mecânica, cinemática, hidráulica, informática, automação, em um ambiente de aprendizagem (STEFFEN, 2009). As atividades desenvolvidas neste ambiente (construção e controle de dispositivos com kits de montar ou matérias como sucata) devem propiciar o manuseio e a construção de novos conceitos.

Aos que buscam viabilizar o conhecimento nas diversas disciplinas escolares e, ao mesmo tempo estimular a experimentação e criatividade, pode recorrer à robótica educativa. Desse modo, o estudante conhece aplicações práticas ligadas a assuntos que estão presentes em seu cotidiano, pois a robótica requer conhecimentos de matemática, geografia, física, mecânica, programação, inglês, dentre outros (CRUZ et al. 2007). Santos e Menezes fazem menção a robótica educativa como um caminho que proporciona aos alunos a capacidade de elaboração de hipóteses, investigação de soluções, resolução de problemas, pensamento computacional e aprendizagem colaborativa.

Nesse contexto a robótica educacional se destaca por disponibilizar demasiadas oportunidades de criar soluções voltadas ao mundo real, possibilitando ao aluno um aprendizado estimulante e dinâmico.

\section{Metodologias utilizadas}

A seguir serão apresentadas as metodologias utilizadas para o ensino de raciocínio logico e pensamento computacional em uma turma de 15 alunos com faixa etária entre 11 e 14 anos. As aulas ocorreram em laboratórios de informática, laboratório interdisciplinar (robótica), salas de aula, pátio e ao ar livre. O curso completo teve a duração de 120 horas, e realizava-se aos sábados de 08:30 às 11:30 da manhã.

\subsection{Atividades Lúdicas e Gamificação}

Um dos objetivos prioritários do curso era preparar os alunos para a competição da OBI. Para tal, o ensino de raciocínio lógico era fundamental, bem como treinamento das provas de edições anteriores. Assim, buscou-se metodologias que atraíssem os alunos a compreensão dos conceitos abstratos à eles. No início das aulas foram realizadas

*Ferramenta gratuita para criação de quiz online 
dinâmicas de conhecimento e 'quebra gelo', onde os alunos puderam se apresentar e conhecer os demais colegas.

Cada aula acontecia em um encontro semanal de 03 horas. Pouco conteúdo teórico era passado, devido a necessidade de exercitar a mente para um raciocínio mais lógico. Porém, ficar apenas resolvendo questões exaustivamente não é o ideal de aula para alunos de ensino fundamental. Assim, ao término de cada aula eram realizadas pequenas dinâmicas que culminariam em uma maratona com ludicidade $\mathrm{e}$ gamificação.As atividades iniciais ocorreram com intuito de revisar os conteúdos para a OBI de maneira mais divertida. A primeira etapa foi um quiz feito na ferramenta online Kahoot* $^{*}$ que simula um jogo, onde cada aluno entra com um nome de jogador e deve responder as questões corretamente o mais rápido possível. Foram 25 perguntas de raciocínio lógico e ao término a equipe vencedora recebeu 20 pontos em seu placar.

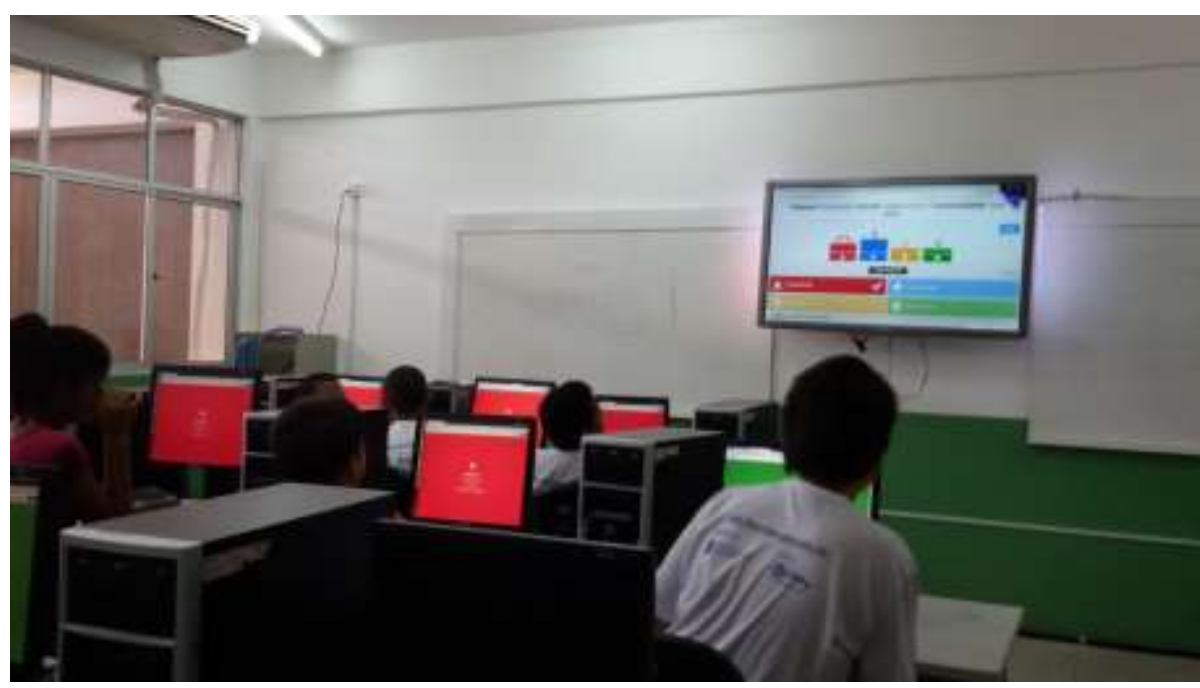

Figure 1. Primeira etapa da maratona - utilização da ferramenta Kahoot.

A ferramenta apesar de simples proporcionou um momento de diversão e desafio. Os alunos responderam as questões sem reclamar, o feedback era imediato, quando acertavam a tela ficava verde, e os mais empolgados gritavam e corriam em comemoração, mas logo tinham que retornar e se concentrar, pois o quiz exigia muita concentração e pensamento rápido.

As etapas seguintes envolviam atividades de raciocínio e físicas, por isso foram realizadas no pátio, e envolveram grande parte da estrutura da instituição. Como os campos e corredores. A segunda prova da maratona consistia em uma corrida, a equipe que chegasse primeiro ao objetivo liberaria uma questão de Raciocínio Lógico que se respondida corretamente somaria a equipe o valor de 50 pontos.

*Ferramenta gratuita para criação de quiz online 
Em seguida outra corrida, porém com caça ao tesouro, a equipe tinha que encontrar um balão que continha uma pergunta. Aquele que encontrasse e trouxesse o balão primeiro, poderia responder a pergunta, caso acertasse teria 100 pontos acrescidos em seu placar. Na última prova prática todos os participantes teriam balões amarrados em seu tornozelo, dentro de cada balão uma pergunta sobre os conteúdos da OBI como mostra a figura 2 . O objetivo era dentro do tempo de 3 minutos tentar estourar a bexiga dos adversários e proteger a sua. Ao término a equipe que tivesse mais perguntas (balões não estourados), poderia responder e somar uma pontuação de até 500. O interessante nesta prova é que uma única equipe conseguiu ficar com todos os balões intactos. Eles montaram uma estratégia de escolher um único adversário e atacar todos juntos, assim também como a defesa. Neste caso a união foi a melhor estratégia e lhes garantiu a vitória.

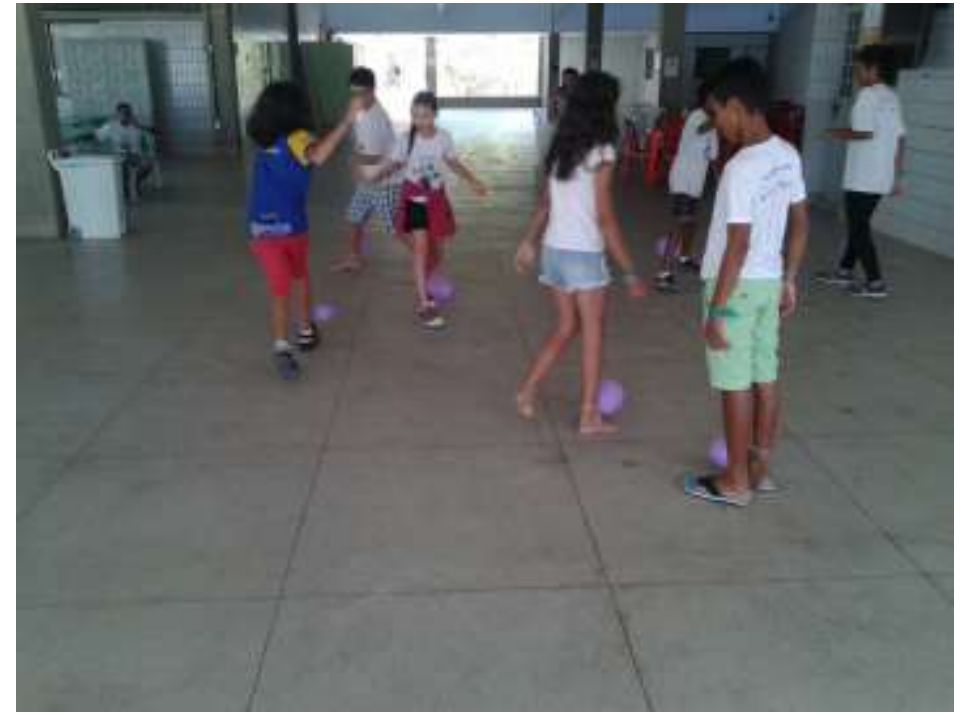

Figure 2. Última etapa da maratona - utilização da Caça ao Tesouro.

Foi observado que os estudantes se sentiram motivados e envolvidos com os conteúdos. As atividades lúdicas e a utilização de mecânicas de jogos (gamificação) na revisão dos conteúdos auxiliou na quebra de tensão provocada pelo período de préprova. A alegria exposta pelos participantes, até mesmo os que não tiveram a pontuação máxima do final, mostra que é possível cativar os alunos com a metodologia adequada (SOARES, 2005).

\subsection{Robótica Educacional}

As aulas de Robótica Educacional se iniciaram após a primeira etapa da prova da OBI. Os alunos foram apresentados ao Kit Lego Mindstorms que é formado por um conjunto de peças da linha tradicional (rodas, tijolos cheios, placas) e da linha Lego Technic (Motores, eixos, engrenagens, correntes, tijolos vazados), acrescido de sensores de toque, intensidade luminosa, som e de temperatura, controlados por um processador programável, denominado módulo NXT.

Também aprenderam o embasamento teórico sobre robótica; o que ela é, para que serve, como utilizá-la, etc. Após o período de aprendizagem inicial eles começaram as montagens. Robôs simples, como carrinhos, garras, guindastes, para conhecerem o funcionamento das peças, motores e sensores. Concomitante a isso foram- apresentados 
conteúdos de programação da ferramenta, com a IDE (Ambiente de Desenvolvimento Integrado) NXT mindstorms 2.0 que funciona de modo intuitivo, trabalhando com programação em blocos.

No decorrer do curso a turma foi convidada a participar da Semana Nacional de Ciência e Tecnologia do IF Sertão PE. Assim iniciaram-se os projetos para apresentação na mesma. Os alunos tiveram a possibilidade de escolher em que queriam trabalhar, sob condição de remeterem a uma disciplina ou demonstrassem sua finalidade social. Quatro projetos foram idealizados pelos estudantes e eram compostos de robôs e maquetes construídas pelos mesmos como vistos na figura 3 abaixo:

1- Robô Coletor de Lixo: O robô tinha o objetivo de remover o lixo de um rio e leva-lo ao local ideal. Sempre pensado na maneira mais rápida e eficaz de realizá-lo. A justificativa dos alunos foi a percepção de que um rio presente no município de Petrolina estava sujo, e deveriam conscientizar as pessoas através de seu projeto.

2- Robô Salva-Vidas: Este objetivava o resgate de uma pessoa em local de risco. O robô deveria localizar a pessoa, captura-la e a levar a um local seguro. Os alunos defenderam seu projeto argumentando que seria arriscado para outras pessoas realizarem o resgate em um local de perigo, pois poderiam colocar a vida de ambas em risco. Assim, o robô seria mais preciso, rápido e eficiente nessa tarefa.

3- Robô Humanoide: é um robô com aparência global, baseada na aparência do corpo humano, permitindo interações com o ambiente, ferramentas ou com o ser humano. Diferente dos projetos anteriores este surgiu com a proposta de atrair o público infanto-juvenil do evento, demonstrando que a realidade da robótica não está distante das pessoas, e que até mesmo crianças podem construir um robô tão atrativo.

4- Robô Escorpião: É um robô com formato de escorpião. Ele reage a movimento, atacando o objeto ou pessoa que interferir em seu caminho. Após inúmeras pesquisas, o grupo responsável por este projeto, percebeu que o escorpião é um animal discreto (desaparece durante e o dia e surge a noite) e hábil (age rapidamente a estímulos), assim defenderam que além da diversão de possuir uma reprodução de um animal que interagisse com o público; eles poderiam utilizar para enviá-lo a locais de risco a humanos portando uma pequena câmera e buscando informações. 


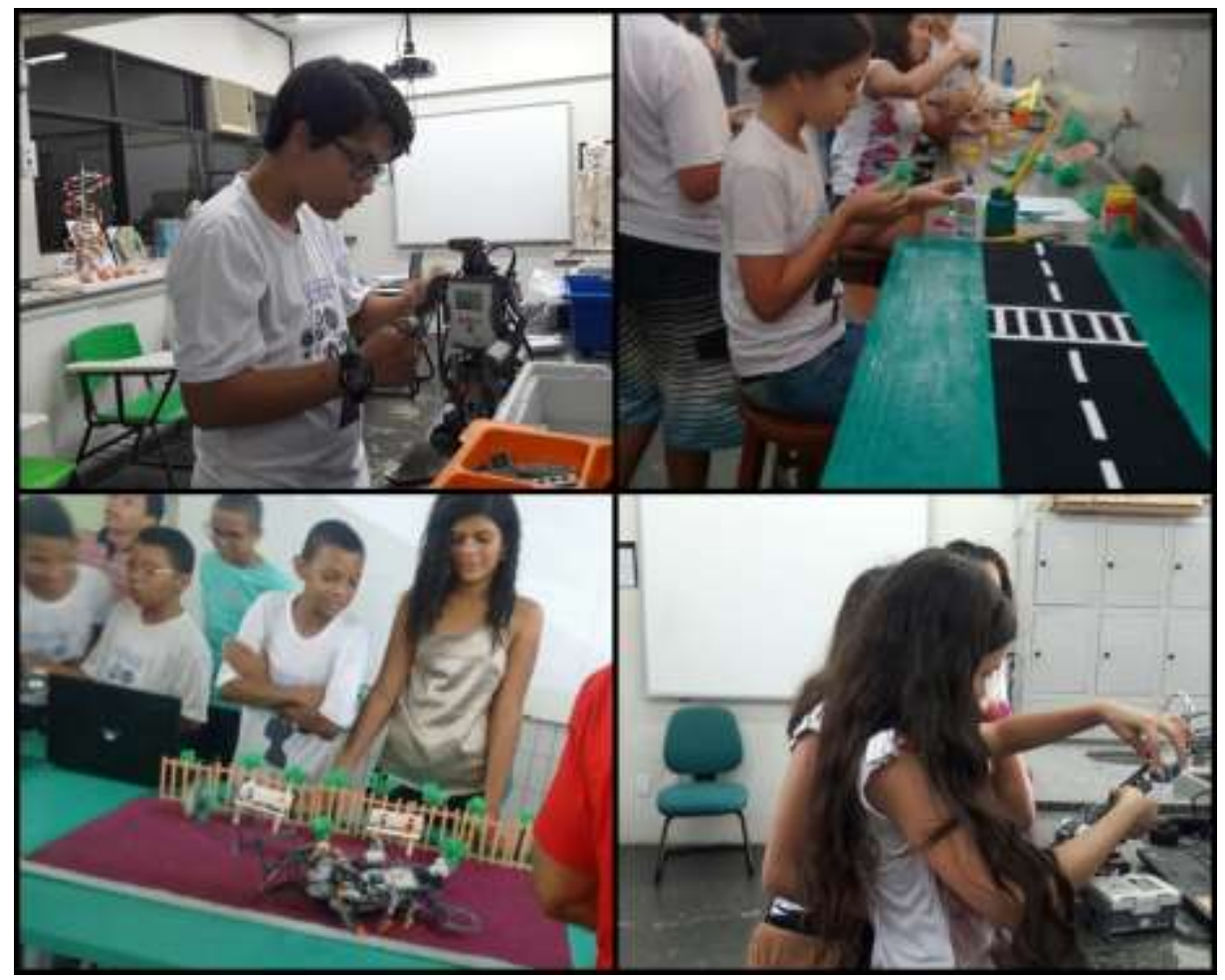

Figure 3. Projetos e Aulas de Robótica Educacional.

Após essa etapa os alunos encerraram o curso e receberam medalhas de honra e a certificação.

\section{Resultados e Considerações Finais}

Os resultados demonstraram que as metodologias aplicadas são excelentes para o aprendizado. A experiência foi satisfatória, pois os alunos se sentiram mais motivados e engajados em todo processo. Exemplo disso é o 'Aluno 1', que não participava das aulas e após a metodologia começou a se envolver, responder questões e criar vínculos de amizade com os demais.

Os resultados podem ser comprovados através da visão dos alunos que foram entrevistados e opinaram sobre o curso: "A minha preferida foi a maratona, quando a professora disse que era ' $p r a$ ' vir de tênis eu até tive vontade de acordar mais cedo." - 'Aluno 2' (11 anos). "Eu adorei a maratona, e também o jogo com as perguntas, foi a melhor aula da minha vida." - 'Aluno 4' (12 anos). "Esse curso é muito bom porque meus pais não tem como pagar um curso desse pra mim e eu recebi de graça, e aprendi robótica e programar que foi o que mais gostei. " 'Aluno 5' (13 anos). "No início estava meio confusa cheguei até a me perguntar "o que eu estou fazendo aqui?" Eu não consegui essa resposta com 1 ou dois dias demorou meses mais hoje eu tenho essa resposta" eu estou realizando um sonho" valeu a pena cada esforço, cada reclamação, acordar cedo nos dias de sábado, a única palavra que tenho em mente agora é GRATIDÃO; gratidão por todos os professores que acordava cedo sem ganhar nada, sei que nada vai retribuir isso, tudo que eu tenho 'pra' dar é um sorriso, um abraço e um obrigado. " - 'Aluno 6' (14 anos). 
Com isso, conclui-se que a abordagem apresentada demonstrou impactos significativos sobre a participação em sala de aula, e também indícios de que aumenta a atenção aos conteúdos. Com estes resultados é possível acreditar que as metodologias apresentadas conseguem aumentar a motivação dos alunos no estudo, tornando-os mais diligentes.

Espera-se que o desenvolvimento de ações como estas venham a acrescentar as pesquisas no país sobre o ensino do Raciocínio Lógico e Pensamento Computacional, como forma de conscientização de sua necessidade, na Educação Básica.

\section{Referências}

A. Orrico. (2012). Mercado brasileiro de games já o quarto maior do mundo e deve continuar a crescer. O Estado de São Paulo, São Paulo. 08 out. 2012. Disponível em: $<$ http://www1.folha.uol.com.br/tec/1165034-mercado-brasileiro-de-games-ja-e-oquarto-maior-do-mundo-e-deve-continuar-a-crescer.shtml>. Acesso em: 01 mai. 2016.

Bitencourt, R. B. (2014). Experiência de gamificação do ensino na Licenciatura em Computação no Sertão Pernambucano. XIII Simpósio Brasileiro de Games e Entretenimento Digital (SBGames 2014).

Blikstein, Paulo. (2008). O pensamento computacional e a reinvenção do computador na educação. Disponível em http://www.blikstein.com/paulo/documents/online/ol_pensamento_computacional.ht $\mathrm{ml}>$ Acesso em: 12 de nov. 2016.

Borges, S. D. S., Reis, H. M., Durelli, V. H., Bittencourt, I. I., Jaques, P. A., \& Isotani, S. (2013). Gamificação aplicada à educação: um mapeamento sistemático. In Brazilian Symposium on Computers in Education (Simpósio Brasileiro de Informática na Educação-SBIE) (Vol. 24, No. 1, p. 234).

Campos, André, Renato Gardiman, and Charles Madeira (2015). "Uma ferramenta gamificada de apoio à disciplina introdutória de programação." $23^{\circ}$ WEI-WORKHOP SOBRE EDUCAÇÃO EM COMPUTAÇÃO.

Cruz, Marcia Elena Jochims Kniphoff da; Lux, Beatriz; Haetinger, Werner; Engelmann, Emigdio Henrique Campos; Horn, Fabiano. (2007). Formação Prática do Licenciando em Computação para Trabalho com Robótica Educativa. In: XVIII Simpósio Brasileiro de Informática na Educação, São Paulo.

CSTA - Computer Science Teacher Association. (2011). "CSTA K-12 Computer Science Standards”. CSTA Standards Task Force. ACM - Association for Computing Machinery.

F. Alves. (2014). Gamification: como criar experiências de aprendizagem engajadoras: um guia completo do conceito à prática. 1 ed. São Paulo: DVS Editora.

Fardo, M. L. (2013). A gamificação aplicada em ambientes de aprendizagem. RENOTE, 11(1).

Fardo, Marcelo Luis. (2013). A gamificação como método: Estudo de elementos dos games aplicados em Processos de ensino e aprendizagem. Dissertação (Mestrado em Educação) - Universidade de Caxias do Sul, Rio Grande do Sul. 
França, R. S., \& do Amaral, H. J. C. (2013). Ensino de computaçao na educaçao básica no brasil: Um mapeamento sistemático. In XXI Workshop sobre Educação em Computação.

G. Zichermann, and C. Cunningham. (2011). Gamification by Design: Implementing Game Mechanics in Web and Mobile Apps. O'Reilly Media.

Johnson, Steven. (2011). De onde vem as boas ideias. Zahar: São Paulo.

Jucá, P., \& Rolim, G. (2013). Gamificação na Disciplina de Empreendedorismo. In XXI Workshop sobre Educação em Computação (WEI) do XXXIII Congresso da Sociedade Brasileira de Computação. Maceió.

K. Werbach, and D. Hunter. (2012). For the Win: How Game Thinking Can Revolutionize Your Business. Wharton Digital Press.

Kapp, Karl. The Gamification of Learning and Instruction: Game-based Methods and Strategies for Training and Education. Pfeiffer, 2012.

L. Sheldon.The Multiplayer Classroom: Designing Coursework as a Game. (2011). Course Technology PTR,

Nunes, D. J. (2008). “Licenciatura em Computação”. Jornal da Ciência, 30 de Maio.

Oliveira, T. M., Bitencourt, R. B., Monteiro, W. M. (2016). Experiências com Gamificação no Ensino de Computação para Jovens e Adultos no Sertão Pernambucano. XV Simpósio Brasileiro de Games e Entretenimento Digital (SBGames 2016).

Rocha Seixas, L., Gomes, A. S., Melo Filho, I. J., \& Rodrigues, R. L. (2014). Gamificação como Estratégia no Engajamento de Estudantes do Ensino Fundamental. In Brazilian Symposium on Computers in Education (Simpósio Brasileiro de Informática na Educação-SBIE) (Vol. 25, No. 1, p. 559).

Santos, Carmen Faria; Menezes, Crediné Silva de. (2005). A Aprendizagem da Física no Ensino Fundamental em um Ambiente de Robótica Educacional. In: Workshop de Informática na Educação / XXV Congresso da Sociedade Brasileira de Computação. São Leopoldo.

Sica, Carlos. (2008). Ciência da Computação no Ensino Básico e Médio. Disponível em $<$ http://www.odiario.com/blogs/carlossica/2011/10/07/ciencia-da-computacaonoensino-medio/ > Acesso em: 22 de out. de 2011.

Smith, A. and Jones, B. (1999). On the complexity of computing. In Advances in Computer Science, pages 555-566. Publishing Press.

Soares, J. F. (2005). Qualidade e equidade na educação básica brasileira: fatos e possibilidades. Os desafios da educação no Brasil. Rio de Janeiro: Nova Fronteira, 91-117.

Steffen, H. H. (2009). Robótica pedagógica na educação: um recurso de comunicação, regulagem e cognição. São Paulo, 2002, 113f (Doctoral dissertation, Dissertação. (Mestrado em Ciências da Comunicação) -Escola de Comunicação e Artes, Universidade de São Paulo, SP, 2002. Disponível em: $<$ http://www. bibvirt. Futuro. usp. br/textos/teses/helo_robotica. pdf>. Acesso em: 12 mar. 2016.

Vianna, Y., Vianna, M., Medina, B., Tanaka, S. (2013). Gamification, Inc.: como reinventar empresas a partir de jogos. MJV Press: Rio de Janeiro. 